\title{
Predicting Academic Performance of College Freshmen in the Philippines using Psychological Variables and Expectancy-Value Beliefs to Outcomes-Based Education: A Path Analysis
}

\author{
Mark M. Alipio * \\ * Faculty of Radiologic Technology, Davao Doctors College, Philippines \\ (e-mail: markalipiorrt@gmail.com)
}

\begin{abstract}
This study was designed to verify the connections between psychological factors, expectancy-value beliefs, and academic performance. A cross-sectional survey was conducted with a systematic sample of 12,452 college freshmen from 70 higher education institutions (HEIs) in the Philippines. Zero-order correlations revealed that psychological factors, expectancy-value beliefs, and academic performance are significantly interrelated with each other. Path analysis revealed that help-seeking, self-esteem, self-efficacy, and social support positively influence expectancy-value beliefs and academic performance. Furthermore, the path analysis showed that academic overload and perceived stress exerted a negative influence on expectancy-value beliefs and academic performance, while expectancy-value beliefs had a positive influence with academic performance. Mediation analysis revealed that expectancyvalue beliefs to OBE partially mediate the effects of the six psychological variables, namely help-seeking, self-esteem, self-efficacy, social support, academic overload and perceived stress, on academic performance. Based on the results of the study, a model that would predict the academic performance of students under OBE approach using psychological factors and expectancy- value beliefs, was developed.
\end{abstract}

Keywords: Academic Performance, College Freshmen, Expectancy-Value Beliefs, OBE, Outcomes-Based Education, Path Analysis, Philippines, Psychological Variables*

${ }^{\star}$ Help-seeking, self-esteem, self-efficacy, social support, academic overload and perceived stress

\section{INTRODUCTION}

Attainment of higher education is an important milestone in a person's life. However, the transition from senior high school to college can be stressful and students' beliefs about their fate during the course of this transition can become a source of stress. Another evolution is the adaptation of college instructors to a new pedagogy called Outcome-Based Education (OBE). In order to be at par with the global teaching-learning methods and competitiveness, the Commission on Higher Education (CHED) required the application of this scheme in Philippine universities and colleges in 2012 through CHED Memorandum Order No. 46. This paradigm of teaching is student-centered rather than lecture-based as in the conventional approach (Crespo et al., 2010). This new approach in education is the main thrust of college institutions in the Philippines today and is adopted to make sure that students and graduates will be well-equipped and prepared for the real world.

One of the goals of the CHED is the attainment of higher human resource number (CHED, 2011). Reducing dropout and increasing completion rates in higher education are two of the key strategies for achieving this goal (NEDA, 2017). Academic failure is a great burden, not only for the society, but also for the higher education institutions (HEls), the students and their families. Data from the CHED (2011, cited by Angara, 2012) revealed that enrollees in HEls from 2001 to the present have reached 2.56 million, but the dropout rate reached an alarming 83.7 percent. This means that the Philippines is producing 2.13 million college dropouts yearly while only 500,000 students are graduating with their respective degrees. The number of dropouts is typically higher among freshmen (Dileep \& Govindarajo, 2013; Ho \& Krishna, 2016; Velez, 2014). This problem kindled some researchers to study the factors that affect students' decision to drop out and they found out lack of self-efficacy, financial constraints and lack of motivation as the strong determinants (Azarcon, Gallardo, Anacin, \& Velasco, 2014; Leonardia, Prytherch, Ronquillo, Nodora, \& Ruppel, 2012; Zerna, Cruz, \& Nuqui, 2014). 
While there were studies about the aforementioned determinants, several scholarly literatures have circulated pointing out the need to know the predictors of academic success to lessen the formidable dropout rate (da Silva, Zakzanis, Henderson, \& Ravindran, 2017; Rumberger \& Ah Lim, 2008; Sæle, 2016). For instance, the psychological factors are considered to be stable and predictable correlates of academic performance and are often suggested as prognosticators of academic achievement in higher education (Krumrei, Newton, Kim, \& Wilcox, 2013; Sommer, 2013).

Psychological factors which have found to have significant association with academic success includes helpseeking, self-esteem, academic overload, perceived stress, self- efficacy and social support (Marasigan II, Dasas, Hernandez, Jayme, \& Alipio; Becirevic, Smojver-Azic, \& Martinac, 2017; Sommer, 2013). Expectancyvalue beliefs, defined by Wentzel and Miele (2016) as the individuals' expectancies for success and the value they have for succeeding, were known to be predictors of academic achievement. Plante, O'Keefe, and The' ore^t (2012) found out that expectancy-value variables predict achievement-related outcomes both directly and indirectly through achievement goals while Azar, Lavasani, Malahmadi, and Amani (2010) revealed a direct, positive influence of expectancy-value beliefs on student's achievement in mathematics subject.

Prior researches have provided empirical evidence which indicates that psychological factors such as selfefficacy are related to expectancy-value beliefs (Florentino, Gustilo, Jailani, Maceren, Periabras, \& Alipio; Doménech-Betoret, Abellán-Roselló, \& Gómez-Artiga, 2017; Williams, 2010). For instance, DoménechBetoret et al. (2017) revealed that students' expectancy-value beliefs played a mediator role between academic self-efficacy and the achievement/satisfaction relationship.

Collectively, there has been a great deal of research support for the central tenets of psychological factors and its impact on academic performance and expectancy-value beliefs as well as expectancy-value beliefs and its impact to academic performance. Based on these evidences that support the direct effects of the relationships presented, this study explores the mediating effects of expectancy-task beliefs to the psychological-academic performance relationship. This study aims to predict the academic performance of students under OBE approach based on specific psychological factors and expectancy-value beliefs. This paper takes consideration of the moderating variables affecting the relationships presented. Hence, this research also focuses on how gender, financial status, type of school in senior high school, academic strand taken during senior high school and enrolled undergraduate degree would affect the correlation between psychological factors and expectancyvalue beliefs, psychological factors and academic performance, and expectancy-value beliefs and academic performance.

In view of the implementation of OBE on the first batch of college students in the Philippines for Academic Year 2018 - 2019, this study seeks to investigate the impact of OBE in learners' beliefs and motivation to complete the entire undergraduate degree. Most of the researches in the Philippines about OBE focused on the improvement of instruction (De Guzman, Edano, \& Umayan, 2017; Espiritu \& Budhrani, 2015; Laguador \& Dotong, 2014; Oreta \& Roxas, 2012) rather than the beliefs of the student in succeeding the new approach of teaching. Thus, it is the aim of the study to predict the relationship of the psychological factors, expectancyvalue beliefs to OBE approach and academic performance of first year students through path analysis, which is a form of structural equation modelling. Finally, this study could serve as reference for further and related researches in the future.

\section{LITERATURE REVIEW}

\section{Outcome-Based Education (OBE)}

The OBE model was developed by William Spady and introduced in the United States of America some 20 years ago. Morcke, Dornan, and Eika (2013) define OBE as an approach to education in which decisions about the curriculum are driven by the outcomes the students should display by the end of the course. Biggs and Tang (2011) viewed it as results-oriented thinking that place the emphasis on the education process and is opposite of input-based education. In other words, in the process of designing programme curriculum, the outcome of learning is stressed and established in advance, that is, what is expected from the learning after the students have graduated in order to equip them with the necessary skills and capabilities before they enter the work place, then going backward with curriculum design, programme outcomes and course outcomes, the development of instructions, delivery modes and appropriate assessments methodologies. 
In the Philippines, Section 5 of the Republic Act 10533: the "Enhanced Basic Education Act of 2013"stated that the Department of Education (DepEd) must coordinate with the Commission on Higher Education (CHED) in crafting the K-12 curricular framework that explicitly requires graduates to show what they may be expected to know, understand and be able to do on the basis of a given qualification (learning outcomes) as well as how qualifications of professionals within a system may move to another. OBE is the instructive design that prepares students meet these professional standards (RA 10533, 2013) . OBE as a curriculum and instructional design and Quality Assurance (QA) framework provides Philippine Education the road map to achieve the overall and long-term desired goal of achieving rapid, inclusive, and sustained economic growth: one that generates jobs and livelihood for, and increase the income of the poor.

\section{Psychological Factors}

Help-seeking is conceptualized as the process of finding and receiving support from others (Karabenick \& Puustinen, 2013). In order for learners to effectively seek help, they first have to identify the problem they need assistance with accept that they need help with a particular problem, and believe that going for help will be useful. Several students, during their time at university, may require psychological or academic assistance to help them with inter-personal, social, academic or career related problems. A study conducted by Payakachat et al. (2013) on student pharmacists revealed that academic helpseeking behavior was positively related to greater perceived academic competence and positive relationships among student pharmacists and faculty members. Regression analysis of Mwavita and Thompson (2006) indicated that help-seeking behavior was a significant predictor of specific academic domains such as calculus.

Self-esteem refers to a person's overall sense of his or her value or worth. It can be considered a measure of how much a person values, approves of, appreciates, prizes, or likes him or herself (McKay, 2009). Few experts define self-esteem as simply one's attitude toward oneself and describe it as a favorable or unfavorable attitude toward the self. A cross sectional study among the second-year undergraduates of Faculty of Health Science, University Kebangsaan Malaysia showed that students with higher selfesteem perform better in their academic (Rosli et al., 2011). A significant positive correlation between academic performance and academic self-efficacy was also found out after investigating 214 psychology students from Taif University and King Abdulaziz University (Alyami et al., 2017).

Academic overload pertains to students' feeling of being dazed by their academic requirements while pursuing a degree at higher education institutions. Academically overloaded students might feel that there is inadequate time to effectively and sufficiently manage all academic tasks such as tests, exams, research assignments, essays and oral presentations. Students' perceptions of the demands of the academic tasks and their discernments of their ability to succeed in completing the tasks influence the amount of effort they put into academic work, and an insufficient amount of effort may lead to academic failure. In fact, difficulties with managing academic workload have been shown to have a negative impact on academic adjustment to university and academic performance (Suhaimi \& Hussin, 2017). Kurata, Bano, and Matias (2015) studied the effects of workload on academic performance among working students in an undergraduate engineering program in Metro Manila, Philippines and recommended interventions to support physical and mental health to better cope in a high workload environment, which will in return translate to better work and academic performance thus an increase in graduation rate.

Students at colleges may experience stress because of intense and demanding academic requirements. When stress is perceived negatively or becomes excessive, it can affect both health and academic performance and can have an adverse effect on students (Cassady, 2010). Moreover, if the pressure is prolonged and perceived as unmanageable, these experiences have been shown to elicit helplessness, depression and stress, thereby placing the academic futures of some students in jeopardy (McIntyre, McIntyre, \& Francis, 2017). Kamarudin et al. (2009) reported a significant correlation between the level of perceived stress at the end of the semester with academic performance and found out that majority of students do not get enough sleep and face nutritional problems throughout the semester in the University of Technology MARA (UiTM), Malaysia.

Self-efficacy refers to student's beliefs in their skill to master new abilities and tasks, often in a specific academic realm (Azar et al., 2010). In other words, perceived self-efficacy is concerned with people's beliefs in their capabilities to produce given achievements (Urdan \& Pajares, 2006). Self-efficacy is described in the theoretical framework of social cognitive theory by Bandura (1977, cited by Norman \& 
Conner, 2017) which stated that human attainment depends on his personal judgement of how well he can perform courses of action required to deal with prospective situations. Kolbe and Bruske (2017) explained that persons with high self- efficacy are able to plan effectively and successfully in completion of a task. Prior researches have provided strong evidence that self-efficacy is a positive predictor of performance outcomes in different subjects (Schunk, Pintrich, \& Meece, 2008; Usher \& Pajares, 2008). For instance, Usher and Pajares (2008) contended that self- efficacy predicts students' academic achievement across academic areas and levels. Students with high self- efficacy are confident to understand a lesson, to solve educational problems, and to select most difficult courses (Sanchez, Outley, Gonzalez, \& Cascante, 2018). The content analysis of students' responses of Ahmad and Safaria (2013) showed that students with high self-efficacy planned to study complex subjects in future. Furthermore, learners with strong senses of self-efficacy tendency involve in challenging responsibilities, contribute more effort and determination, and show outstanding academic performance in comparison with students who lack such confidence (Azar et al., 2010).

Social support is the physical and emotional comfort given by family, friends, co-workers and others. Adequate social support for students is beneficial in helping and supporting them in their transition from high school to college, as well as adjusting to the new demands, tasks, responsibilities and requirements of higher education life. Findings of the study of de la Iglesia, Stovera, and Liporacea (2014) showed that a higher perception of social support would be related to a better academic achievement. Structural equation modeling analysis of Dupont, Galand, and Nils (2015) revealed that institutional and supervisor support were associated with motivation, which in turn predicted greater behavioral, cognitive and emotional engagement. Correlation analysis was carried out to measure the relationship between social support and academic performance of 272 Madonna University students and results of correlation analysis indicated that there was a positively significant relationship between social support and academic performance (Ogbeide \& Ugwu, 2016). In order words, the higher the social support availed and accessed, the higher the quality of academic performance delivered.

\section{Expectancy-Value Beliefs}

Expectancy-value belief is grounded by expectancy-value theory which was originally created in order to describe and predict individual's attitudes toward objects and actions. Established in the social cognitive perspective of motivation, the theory started in the 1930 s with Lewin and Tolman, and it was further developed into a general model of achievement motivation by Atkinson (Schunk et al., 2008). According to the basic theory, achievement behavior can be looked upon as a function of the expectancies for a student, the goals toward which he/she is working and the task value of the student. Expectancy refers to an individual's belief about how well he/she will do on upcoming tasks, and values refer to the reasons for doing an activity. When the student has more than one choice, he or she will choose the option with the best possible combination of expected success and value.

According to expectancy-value theory, students' achievement and achievement related choices are most proximally determined by two factors, expectancies for success, and subjective task values (Eccles, 2009). Expectancies are specific beliefs individuals have regarding their success on certain tasks they will carry out in the short-term future or long-term future. According to Eccles and colleagues, subjective task value can be thought of the motivation that allow an individual to answer the question "Do I Want to do This Activity and Why?". The modern expectancy-value distinguishes four task-value components: interest value (enjoyment people have doing a task or intrinsic interest in task content), attainment value (importance of doing well on a task), utility value (usefulness of the task for future goals), relative cost (perceived negative aspects of engaging in the task).

Previous researches linked expectancy-value beliefs to outcomes of student in the academic setting. Freshmen students from Netherlands and Flanders were used to study the application of the Expectancy Value Model and it significantly predicted student achievement as a function of expectancies, motivation to be successful, previous experience, and social and cultural environment (Verhoeven, 2010). Results from the first multivariate analysis of variance (MANOVA) of Neuville, Frenay, and Bourgeois (2007) with task value and self-efficacy as independent variables only showed a main effect of task value on all learning strategies and behavioral outcomes. Results also supported the fourth theoretical approach of the theory suggesting that expectancy-value variables predict achievementrelated outcomes both directly and indirectly through achievement goals (Plante et al., 2012). 


\section{Academic Performance}

Academic performance is measured by the evaluation of how much has been achieved over a certain period of time (von Stumm, Hell, \& Premuzic, 2011). Cumulative GPA and completion of educational benchmarks such as secondary school diplomas and bachelor's degrees represent academic achievement. Much research shows that academic performance is a major determinant of retention and graduation (Ball, Dyer, \& Garton, 2002; Garton, Dyer, \& King, 2001; Kennett \& Reed, 2009). These researchers also found out that the grade point average is usually found to be a significant predictor of academic achievement.

\section{OBJECTIVES}

This study seeks to explain the relationship between the following variables: psychological factors and academic performance, expectancy-value beliefs and academic performance, and psychological factors and expectancy-value beliefs. Furthermore, it seeks to determine the mediating effects of expectancyvalue beliefs to psychological factors-academic performance relationship. Finally, this study aims to develop a model that would predict the academic performance of students under OBE approach using psychological factors and expectancy- value beliefs.

\section{HYPOTHESES}

The hypothesis to be tested in the present study states that expectancy-value beliefs mediate the effect of students' help-seeking, self-esteem, academic overload, perceived stress, self-efficacy and social support on their academic performance (as depicted in Figure 1). The hypothesized relations between the variables are:

- Help-seeking, self-esteem, self-efficacy and social support will have positive associations with expectancy-value beliefs and academic performance. These positive associations would indicate that students who sought help with difficulties they experienced during the year, displayed a high level of self-esteem and self-efficacy and received more support from other people will have higher expectancyvalue beliefs and will achieve a higher level of academic performance.

- Academic overload and perceived stress will have negative associations with expectancy-value beliefs and academic performance. These negative associations would indicate that students who displayed high levels of academic overload and perceived stress will show lower level of expectancy-value beliefs and will achieve a lower level of academic performance.

- Expectancy-value beliefs will have a positive association with academic performance, indicating that participants who displayed a high level of expectancy-value beliefs will tend to achieve a higher level of academic performance.

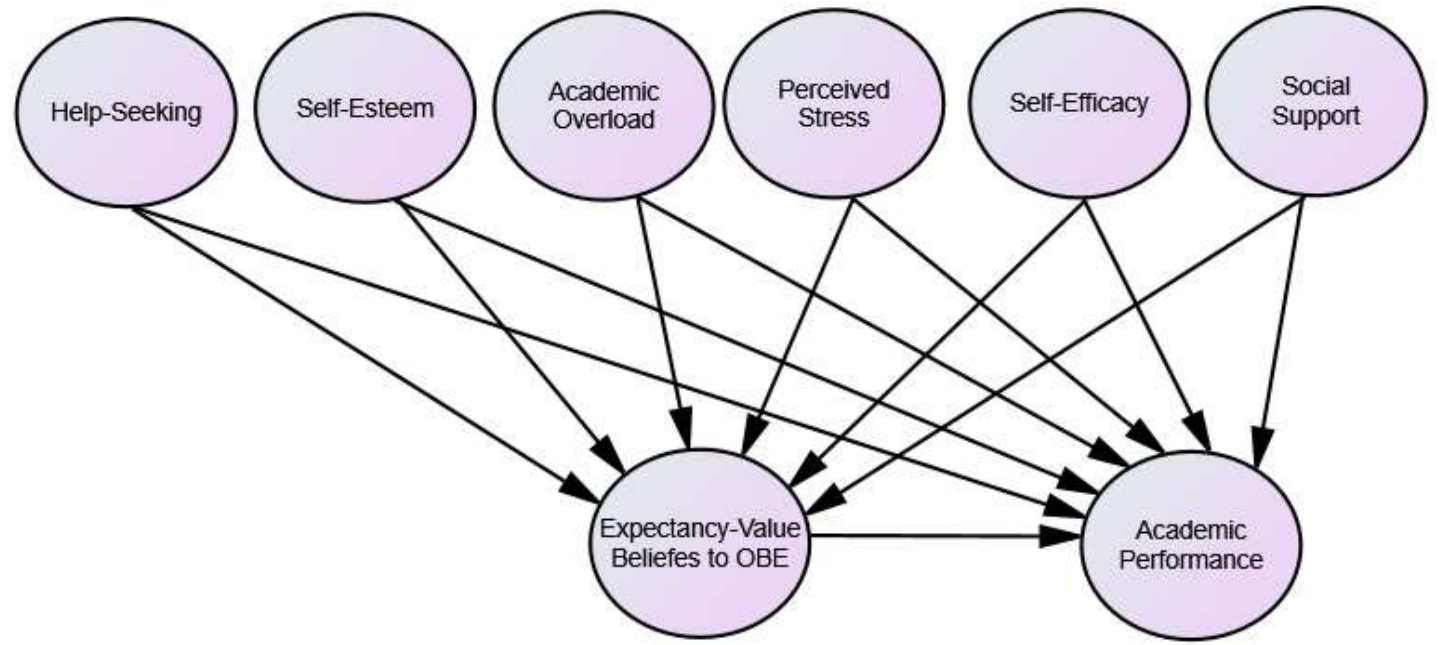

Figure 1. Conceptual Model 


\section{METHODOLOGY}

\section{Design and Setting}

This study used descriptive correlational design to describe and measure the degree of the following relationships: psychological factors and academic performance, psychological factors and expectancyvalue beliefs, and expectancy-value beliefs and academic performance. In this design, subjects' scores on two variables were measured, without manipulation of any variables, to determine whether there is an association (Creswell, 2014).

A total of 70 higher education institutions (HEIs) in the Philippines were sampled. The participants of this study were the freshmen students of the institutions who entered the First Semester, Academic Year 2018-2019 and who were enrolled as regular students to their respective programs. Systematic random sampling technique was employed in the study and every $5^{\text {th }}$ sample in the frame of students was selected. A power analysis using G*Power 3.1 (Faul, Erdfelder, Buchner, \& Lang, 2013) was used to determine the sample size needed to attain a minimum power of 0.80 . Using the power analysis, a total of 12,452 students were recruited as respondents in the study.

\section{Measures}

The present study employed a number of quantitative self-report measures to assess the independent and mediator variables. The students' academic performance as dependent variable is conceptualized as the Weighted Point Average (WPA) which was directly obtained from the respondents. The scales used for the present study are discussed in the following sections.

Help-seeking. Help seeking was assessed using an adaptation of a 6-item help seeking attitude scale developed by Knapp and Karabenick (1991). Changes were made on the item statements and options to fit the circumstances of the study. That is, the word "tutoring" was replaced with the word "help". The answer format used was a Likert scale ranging from 1 (strongly disagree) to 6 (strongly agree). Knapp and Karabenick (1991) reported a reliability of 0.74 for the 6-item scale.

Self-esteem. Rosenberg's Self-Esteem Scale (Rosenberg, 1965) was utilized to measure self-esteem. The Rosenberg Self-Esteem Scale consists of 10 items measuring the participant's global self-esteem ( $\alpha$ $=.83$ ). The answer format used is a Likert scale ranging from 1 (strongly disagree) to 4 (strongly agree). The scale was scored such that a high score corresponds with a high level of self-esteem.

Academic Overload. Academic overload was measured via the 5-item scale used by Petersen (2006). The scale is a $5^{-}$point Likert scale that requires respondents to indicate the extent to which the statements apply to them. Responses ranged from 'does not apply at all' to 'applies completely'. Scores on this scale ranged from 1 to a maximum of 5 . Responses were scored such that a high score corresponds with a high level of academic overload, that is, the academic requirements are perceived to be very demanding and the student is unable to cope. Petersen (2006) reported a 0.75 reliability coefficient of the scale.

Perceived Stress. The Perceived Stress Scale (PSS), as developed by Cohen, Kamarck, and Mermelstein (1983), was used. This scale measured the degree to which situations in one's life are appraised as stressful. Monroe and Kelley (1997) state that the PSS is the only empirically established index for the general appraisal of perceived stress. The 14 items of the PSS were designed to measure the degree to which respondents found their lives unpredictable, uncontrollable, and overloading. Responses were scored such that a high score corresponds with a high level of perceived stress. Cohen et al. (1983) reported reliability coefficients that lie between 0.83 and 0.87 for this scale.

Self-efficacy. The Academic Self-Efficacy Scale, as developed by Klobas, Renzi, and Nigrelli (2007) was utilized. These 10 item-scale was assessed on a seven-point Likert-type scale ranging from 1 (I am definitely not able to do this) to 7 (I am definitely able to do this). The internal consistency of this scale has been reported as 0.84 (Cronbach Alpha), which shows good internal consistency (Klobas et al., 2007). 
Social support. The Support Questionnaire, designed by Lozada-Santone (2001), measures students perception of their social support from four sources: parents, instructors, close friends, and other adults. The Support Questionnaire consists of 36 items, a total score on all sources of support is tallied using a 3 -point Likert scale, rated as 3 = very helpful, supportive or encouraging, $2=$ sometimes helpful, or supportive or encouraging or $1=$ not helpful, supportive or encouraging. The Support Questionnaire has a strong internal consistency; a Cronbach's alpha of 0.912 was reported by the developer of the scale (Lozada-Santone, 2001).

Expectancy-value Beliefs. Student expectancy beliefs and task values were measured using a modified Expectancy-Value Questionnaire (Eccles, 2009) and Valuing of Education (VOE) Scale (Hagemeie \& Murawski, 2014). A 5-item questionnaire was extracted from the modified ExpectancyValue Questionnaire to measure the expectancies of students while a 24-item questionnaire was extracted from the VOE scale to measure the beliefs on the following task values: interest, attainment value, utility value and relative cost. Xiang, McBride, and Bruene (2006) have reported that ExpectancyValue Questionnaire could produce reliable data with the Cronbach alpha coefficients ranging from 0.63 to 0.87. Hagemeie and Murawski (2014) have also reported the following Cronbach alpha coefficients: 0.88 for interest, 0.84 for attainment value, 0.76 for utility value and 0.70 for relative cost.

\section{Procedure}

Firstly, letter permissions were obtained from the HEIs in order to conduct the research. After confirmation, permission was then requested from the head of the programs of the college and the relevant course coordinators and lecturers to approach students in their first-year lectures in order to invite participants to volunteer for the study. Once permissions were obtained, students were approached in lectures by the researcher, who verbally invited students to participate in the study and briefly explained the nature of participation. After students signed the consent form, they were given the survey questionnaire to elicit responses. After the questionnaires were retrieved, the responses were tabulated, analyzed and interpreted using the statistical tools.

\section{Statistical Tools}

Descriptive and Inferential Statistics. Mean and frequencies were used in order to describe the sample and the basic data obtained. Tests for normality (Kolmogorov-Smirnov tests) were conducted on the data to assess whether or not the data is normally distributed in order for parametric tests to be used. Because the majority of the data were normally distributed, parametric tests were run, namely Pearson's correlations and multiple regression. Pearson's correlation was used to show the relationship between variables while multiple regression was used to provide an indication of the extent to which a predictor variable relates to and can therefore be used to predict a criterion variable.

Path Analysis. Path analysis, which belongs to a family of statistical techniques known as structural equation modelling (SEM), was used to predict regression weights. The regression weights predicted during path analysis were then compared to the observed correlation matrix. Path analysis was chosen as the technique for this study for a number of reasons: in order for the result of this study to be replicated and extended in the future researches and as the variable of expectancy-value beliefs in the hypothesized model acts as both, a criterion of multiple independent variables and predictor variable to academic performance, alternative statistical techniques cannot be applied. Before formulating the path analysis, the following assumptions were identified first and met: linearity, additivity, causality, measurement error, lack of multicollinearity, error term, recursiveness, measurement level, specification error and sample size. 


\section{RESULTS}

Descriptive statistics of all the variables are presented in Table 1 . The outcome measures indicate that the average academic performance as measured by WPA for the sample was $82.22 \%(\mathrm{SD}=4.23)$ and the respondents reported an average of $2.99(\mathrm{SD}=0.32)$ expectancy-value beliefs to OBE, which roughly means that they sometimes believe that their academic success is attributed to OBE learning. Means and standard deviations for psychological variables are also reported in Table 1. On average, the respondents display a medium amount of help-seeking (mean $=3.21, \mathrm{SD}=0.21$ ), self-esteem (mean=3.33, $\mathrm{SD}=0.25$ ), academic overload (mean=3.12, $\mathrm{SD}=0.65$ ), perceived stress $($ mean=3.10, $\mathrm{SD}=0.34)$, self-efficacy $(\mathrm{mean}=3.03, \mathrm{SD}=0.54)$, and social support $(\mathrm{mean}=2.89$, $\mathrm{SD}=0.33)$.

Table 1 also shows the correlations among psychological variables, expectancy-value beliefs to OBE, and academic performance. Help-seeking is positively related to self-esteem, self-efficacy, social support, expectancy-value beliefs to OBE, and academic performance whereas negatively related to academic overload and perceived stress. Self-esteem is positively related to self-efficacy, social support, expectancy-value beliefs to OBE, and academic performance but negatively related to academic overload and perceived stress. Academic overload is negatively related to self-efficacy, social support, expectancy-value beliefs to OBE, and academic performance but positively related to perceived stress. Perceived stress is negatively related to self-efficacy, social support, expectancyvalue beliefs to OBE, and academic performance. Self-efficacy is positively related to social support, expectancy-value beliefs to OBE, and academic performance. Social support is positively related to expectancy-value beliefs to OBE and academic performance. Finally, expectancy-value beliefs to OBE is positively related to academic performance.

\section{Table 1}

Means, standard deviations, Cronbach's alphas, and Zero-order Correlations

\begin{tabular}{|c|c|c|c|c|c|c|c|c|c|c|c|}
\hline Variables & $\alpha$ & $\mathbf{M}$ & SD & $\mathbf{1}$ & 2 & 3 & 4 & 5 & 6 & 7 & 8 \\
\hline 1 Help-Seeking & .89 & 3.21 & .21 & - & .81 & -.84 & -.85 & .74 & .79 & .69 & .77 \\
\hline 2 Self-Esteem & .95 & 3.33 & .25 & & - & -.81 & -.91 & .69 & .69 & .72 & .69 \\
\hline 3 Academic Overload & .92 & 3.12 & .65 & & & - & .71 & -.77 & -.70 & -.78 & -.92 \\
\hline 4 Perceived Stress & .90 & 3.10 & .34 & & & & - & -.67 & -.69 & -.81 & -.90 \\
\hline 5 Self-Efficacy & .92 & 3.03 & .54 & & & & & - & .82 & .91 & .69 \\
\hline 6 Social Support & .91 & 2.89 & .33 & & & & & & - & .69 & .84 \\
\hline 7 Expectancy-Value Beliefs & .88 & 2.99 & $\begin{array}{l}.35 \\
.32\end{array}$ & & & & & & & - & $\begin{array}{l}.04 \\
.97\end{array}$ \\
\hline 8 Academic Performance & & 82.22 & 4.23 & & & & & & & & - \\
\hline
\end{tabular}

A path analysis was conducted to determine the causal effects among psychological variables, expectancy-value beliefs to OBE, and academic performance. The conceptual model, presented in Fig. 1, was consistent with the empirical data. More specifically, all path coefficients are significant at the .05 level. The significant paths are as follows: expectancy-value beliefs to OBE and academic performance paths in the help-seeking, self-esteem, self-efficacy, social support, academic overload and perceived stress $(\mathrm{p}<0.05)$; and academic performance path in the expectancy-value beliefs to OBE $(\mathrm{p}<0.05)$.

The hypothesized conceptual model with path coefficients was generated and is now presented in Figure 2. The model fits well with the following indexes: Chi-square of Minimum Discrepancy Test (9.06), $\mathrm{p}<0.000 ; \mathrm{CFI}=0.952 ; \mathrm{GFI}=0.971 ; \mathrm{NFI}=0.977$; $\mathrm{SRMR}=0.065$, RMSEA $=0.03$. 


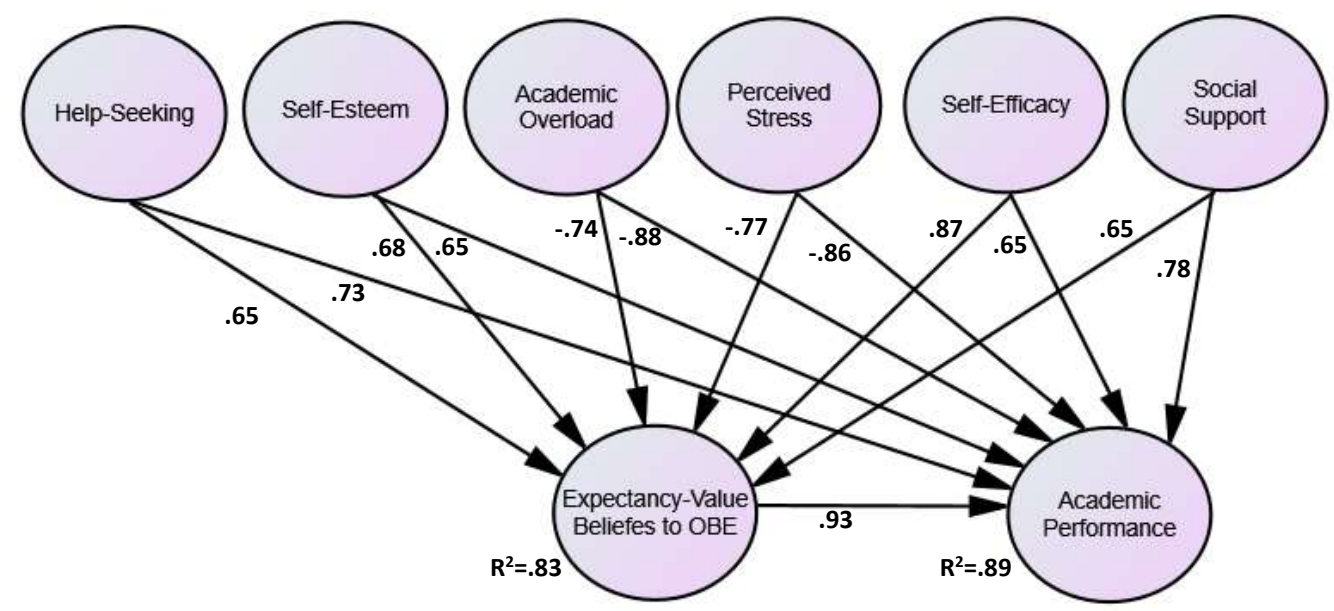

Figure 2. Path Diagram of the Conceptual Model

The outcome of primary interest was academic performance: the determinant with the largest total causal effect is expectancy-value beliefs to OBE (.93), followed by academic overload (-.88), perceived stress (-.86), social support (.78), help-seeking (.73), self-esteem (.65), and self-efficacy (.78). It can be gleaned that academic overload and perceived stress exerted a negative influence on academic performance, while help-seeking, self-esteem, self-efficacy, social support, and expectancy-value beliefs to OBE exerted a positive influence on academic performance. Approximately $89 \%$ of the variance in the academic performance is explained by the model.

Another outcome of secondary interest is expectancy-value beliefs to OBE itself: the determinant with the largest total causal effect is self-efficacy (.87), followed by perceived stress (-.77), academic overload (-.74), self-esteem (.68), help-seeking (.65), and social support (.65). It can be gleaned that academic overload and perceived stress exerted a negative influence on expectancy-value beliefs to OBE, while help-seeking, self-esteem, self-efficacy, and social support exerted a positive influence on expectancy-value beliefs to OBE. Approximately $83 \%$ of the variance in the expectancy-value beliefs to OBE is explained by the model.

A mediation analysis was further conducted to determine the mediating effects of expectancy-value beliefs to psychological factors-academic performance relationship. When expectancy-value beliefs to OBE variable is included as mediator in the model, all psychological variables, as well as expectancy-value beliefs to OBE, exerted a significant influence on academic performance $(p<0.05)$. This indicates that expectancy-value beliefs to OBE partially mediate the effects of the six psychological variables, namely help-seeking, self-esteem, self-efficacy, social support, academic overload and perceived stress, on academic performance.

\section{DISCUSSION}

The main objective of the present study was to explain the relationship among psychological factors, expectancy-value beliefs, and academic performance. Additionally, the study sought to determine the mediating effects of expectancy-value beliefs to psychological factors-academic performance relationship. The main outcome of the study was the development of a model that would predict the academic performance of students under OBE approach using psychological factors and expectancy-value beliefs. In an attempt to answer the objectives, three hypotheses were tested and presented sequentially as follows:

Hypothesis 1: Help-seeking, self-esteem, self-efficacy and social support will have positive associations with expectancy-value beliefs and academic performance.

Consistent with the previous studies (Becirevic et al., 2017; Sommer, 2013), the findings of the study indicate that help-seeking, self-esteem, self-efficacy, and social support positively influence expectancy- 
value beliefs and academic performance. These positive associations would indicate that students who sought more help with difficulties they experienced during the year, displayed a high level of selfesteem and self-efficacy and received more support from other people will most likely have higher expectancy- value beliefs and will achieve a higher level of academic performance. Conversely, students who sought less help with difficulties they experienced during the year, displayed a low level of self-esteem and self-efficacy and received less support from other people will most likely have lower expectancy- value beliefs and will achieve a lower level of academic performance.

Hypothesis 2: Academic overload and perceived stress will have negative associations with expectancy-value beliefs and academic performance.

The results showed that academic overload and perceived stress exerted a negative influence on expectancy-value beliefs and academic performance. The findings, consistent with prior research (Doménech-Betoret et al., 2017; Williams, 2010), suggest that students who displayed high levels of academic overload and perceived stress will show lower level of expectancy-value beliefs and will achieve a lower level of academic performance. Conversely, students who displayed low levels of academic overload and perceived stress will show higher level of expectancy-value beliefs and will achieve a higher level of academic performance.

Hypothesis 3: Expectancy-value beliefs will have a positive association with academic performance.

Consistent with prior studies (Plante et al., 2012; Verhoeven, 2010), the present study revealed that expectancy-value beliefs had a positive influence with academic performance. This indicates that students who displayed a high level of expectancy-value beliefs will tend to achieve a higher level of academic performance. On the other hand, students who displayed a low level of expectancy-value beliefs will tend to achieve a lower level of academic performance.

The findings of the mediation analysis revealed that expectancy-value beliefs to OBE partially mediate the effects of all psychological variables in the model, namely help-seeking, self-esteem, self-efficacy, social support, academic overload and perceived stress, on academic performance. In other words, help-seeking, self-esteem, self-efficacy, social support, academic overload and perceived stress contributes directly to explain the variation in the academic performance and indirectly via the expectancy-value beliefs to OBE.

\section{LIMITATIONS AND DIRECTIONS FOR FUTURE RESEARCH}

This study was designed to verify the connections between psychological factors, expectancy-value beliefs, and academic performance. The sample is thus limited to college freshmen students who enrolled in a lecture-based introductory level class. Tests of the association between expectancyvalue beliefs to $\mathrm{OBE}$ and academic performance should be expanded to other teaching modes (e.g., seminars) as well as other educational institutions (e.g., a non-Filipino university) in order to fully understand the impact of psychological factors and expectancy-value beliefs to OBE and academic performance. Although the path analysis helps with clarifying the causality claims, future research should utilize a time-sequence design to further establish the causal order (e.g. testing the relationship between self-reported psychological factors and expectancy-value beliefs measured around first semester and second semester). Finally, the survey method relies on students' selfreport of their psychological factors and expectancy-value beliefs to OBE. Future research can take advantage of other methods to increase the accuracy of psychological factors and expectancy-value beliefs to OBE measures.

Despite these limitations, the findings generally concur with prior research in discerning the roles of psychological factors and expectancy-value beliefs to OBE without claiming an overall positive to negative effect of academic performance. It is proposed that strategies should be undertaken to reduce academic overload and perceived stress of the students, so as to improve academic performance, without compromising the learning objectives and necessary competencies. On the other hand, sustainable measures that promote help-seeking, self-esteem, self-efficacy, and social support may be implemented to enhance the performance of the students in the academic milieu. 
Meanwhile, expectancy-value beliefs to outcomes-based education (OBE), student's beliefs about how well he/she will do on upcoming tasks, and reasons for doing an activity, should be strengthened by improving the instructional materials of OBE approach. Hence, capacitation of the teachers through trainings and continuous quality measures monitoring of the school administrators are of paramount importance. This paper suggests that intensifying school programs and initiatives pertaining to the six psychological variables and expectancy-value beliefs to outcomes-based education could help to improve the academic performance of the students.

\section{REFERENCES}

Ahmad, A., \& Safaria, T. (2013). Effects of Self-Efficacy on Students' Academic Performance. Journal of Educational, Health and Community Psychology, 2(1). doi:http://dx.doi.org/10.12928/jehcp.v2i1.3740

Alipio, M. M., Felizarte L. P., \& Revilla, D. L. Outcomes-Based Education Approach Correlates and Academic Performance of College Radiologic Technology Freshmen.

Alyami, M., Melyani, Z., Al Johani, A., Ullah, E., Alyami, H., Sundram, F., . . Henning, M. (2017). The Impact of Self-Esteem, Academic Self-Efficacy and Perceived Stress on Academic Performance: A Cross-Sectional Study of Saudi Psychology Students. European Journal of Educational Sciences, 4, 51- 68. doi:10.19044/ejes.v4no3a5

Angara, E. (2012). An Act Providing for Free College Entrance Examinations to Underpriveleged Public High School Students Belonging to the Top Ten Percent (10\%) of the Graduating Class. Pasay City, Philippines Retrieved from https://www.senate.gov.ph/lisdata/1476012283!.pdf.

Azar, H., Lavasani, M., Malahmadi, E., \& Amani, J. (2010). The role of self- efficacy, task value, and achievement goals in predicting learning approaches and mathematics achievement. Procedia Social and Behavioral Sciences, 5, 942-947. doi:https://doi.org/10.1016/j.sbspro.2010.07.214

Azarcon, D., Gallardo, C., Anacin, C., \& Velasco, E. (2014). Attrition and Retention in Higher Education Institution: A Conjoint Analysis of Consumer Behavior in Higher Education. Asia Pacific Journal of Education, Arts and Sciences, 5(5).

Ball, A., Dyer, J., \& Garton, B. (2002). The Academic Performance And Retention Of College Of Agriculture Students (Vol. 43).

Bandura, A. (1977). Social learning theory: Prentice Hall.

Becirevic, I., Smojver-Azic, S., \& Martinac, T. (2017). Predictors of University Students' Academic Achievement: A Prospective Study. Faculty of Humanities and Social Sciences, Rijeka. doi:https://doi.org/10.5559/di.26.4.01

Biggs, J., \& Tang, C. (2011). Teaching For Quality Learning At University: McGraw-Hill Education.

Cassady, J. C. (2010). Anxiety in Schools: The Causes, Consequences, and Solutions for Academic Anxieties: Peter Lang.

CHED. (2011). Comission on Higher Education (CHED) Strategic Plan for 2011-2016. Manila, Philippines Retrieved from https://ched.gov.ph/.

Cohen, S., Kamarck, T., \& Mermelstein, R. (1983). A global measure of perceived stress. Journal of Health \& Social Behavior, 24, 385-396. 
Crespo, R., Najjar, J., Derntl, M., Leony, D., Neumann, S., Oberhuemer, P., . . Kloos, C. (2010). Aligning assessment with learning outcomes in outcome-based education. Education Engineering (EDUCON), 1239-1246.

Creswell, J. (2014). Research Design: Qualitative, Quantitative, and Mixed Methods Approaches: SAGE Publications.

da Silva, T., Zakzanis, K., Henderson, J., \& Ravindran, A. (2017). Predictors of Post-Secondary Academic Outcomes among Local-Born, Immigrant, and International Students in Canada: A Retrospective Analysis. Canadian Journal of Education, 40(4).

De Guzman, M., Edano, D., \& Umayan, Z. (2017). Understanding the Essence of the OutcomesBased Education (OBE) and Knowledge of its Implementation in a Technological University in the Philippines. Asia Pacific Journal of Multidisciplinary Research, 5(4).

de la Iglesia, G., Stovera, J., \& Liporacea, M. (2014). Perceived Social Support and Academic Achievement in Argentinean College Students. Europe's Journal of Psychology, 10(4). doi:10.5964/ejop.v10i4.777

Dileep, K., \& Govindarajo, N. (2013). Indicative variables of attrition: Application of Delphi Technique. La Pensee Journal, 75(12), 184-201.

Doménech-Betoret, F., Abellán-Roselló, L., \& Gómez-Artiga, A. (2017). Self-Efficacy, Satisfaction, and Academic Achievement: The Mediator Role of Students' Expectancy-Value Beliefs. Frontiers in Psychology, 8, 1193. doi:10.3389/fpsyg.2017.01193

Dupont, S., Galand, B., \& Nils, F. (2015). The impact of different sources of social support on academic performance: Intervening factors and mediated pathways in the case of master's thesis. Revue Européenne de Psychologie Appliquée/European Review of Applied Psychology, 65(5), 227237. doi:https://doi.org/10.1016/j.erap.2015.08.003

Eccles, J. S. (2009). Who am i and what am i going to do with my life? Personal and collective identities as motivators of action. Educ. Psychol, 44, 78-89. doi:10.1080/00461520902832368

Espiritu, J., \& Budhrani, K. (2015). Implementing an Outcome-Based Education (OBE) Framework in the Teaching of Industrial Psychology. DLSU Research Congress.

Faul, F., Erdfelder, E., Buchner, A., \& Lang, A. (2013). Statistical Power Analyses Using G*Power 3.1: Tests for Correlation and Regression Analyses. doi:https://doi.org/10.3758/BRM.41.4.1149

Florentino, C. B., Gustilo, R. L., Jailani, H. U., Maceren, M. R., Periabras, N. O., \& Alipio, M. M. The Clinical Competencies of Radiologic Technology Interns of Batch 2018-2019 on Radiological Science Modalities: Basis for Proposed Enhancement Program. Retrieved from https://www.academia.edu/40139502/The_Clinical_Competencies_of_Radiologic_Technology _Interns_of_Batch_2018-

2019_on_Radiological_Science_Modalities_Basis_for_Proposed_Enhancement_Program

Garton, B. L., Dyer, J. E., \& King, B. O. (2001). Factors Associated with the Academic Performance and Retention of College Agriculture Students. NACTA Journal, 45(1), 21-27.

Hagemeie, N., \& Murawski, M. (2014). An Instrument to Assess Subjective Task Value Beliefs Regarding the Decision to Pursue Postgraduate Training. American Journal of Pharmaceutical Education, 78(1). doi:10.5688/ajpe78111 
Ho, T., \& Krishna, D. (2016). Risk Factors Associated with First-Year College Dropout. Poster session presented at Virginia Commonwealth University Poster Symposium for Undergraduate Research and Creativity, Richmond, VA.

Kamarudin, R., Aris, A., Norzaidi, M., Chong, S.-C., Mohamed, I., \& Ibrahim, N. (2009). The impact of perceived stress and stress factors on academic performance of pre-diploma science students: a Malaysian study (Vol. 2).

Karabenick, S. A., \& Puustinen, M. (2013). Advances in HelpSeeking Research and Applications: The Role of Emerging Technologies: Information Age Publishing.

Kennett, D. J., \& Reed, M. J. (2009). Factors influencing academic success and retention following a 1st-year post-secondary success course. Educational Research and Evaluation, 15(2), 153-166. doi:10.1080/13803610902804382

Klobas, J., Renzi, S., \& Nigrelli, M. (2007). A scale for the measurement of self-efficacy for learning (SEL) at university. "Carlo F. Dondena" Centre for Research on Social Dynamics (DONDENA), Università Commerciale Luigi Bocconi. doi:https://ideas.repec.org/p/don/donwpa/oo2.html

Knapp, J. R., \& Karabenick, S. A. (1991). Relationship of academic help seeking to the use of learning strategies and other instrumental achievement behaviour in college students. Journal of Educational Psychology, 83(2), 221-230. doi:10.1037/0022-0663.83.2.221

Kolbe, K., \& Bruske, A. (2017). Business is Business: Reality Checks for Family-Owned Companies: Greenleaf Book Group Press.

Krumrei, E., Newton, F., Kim, E., \& Wilcox, D. (2013). Psychosocial Factors Predicting First-Year College Student Success. Journal of College Student Development, 54, 247-266. doi:10.1353/csd.2013.0034

Kurata, Y. B., Bano, R. M. L. P., \& Matias, A. C. (2015). Effects of Workload on Academic Performance among Working Students in an Undergraduate Engineering Program. Procedia Manufacturing, 3, 3360- 3367. doi:https://doi.org/10.1016/j.promfg.2015.07.497

Laguador, J., \& Dotong, C. (2014). Knowledge versus Practice on the Outcomes-Based Education Implementation of the Engineering Faculty Members in LPU. International Journal of Academic Research in Progressive Education and Development, 3(1).

Leonardia, J. A., Prytherch, H., Ronquillo, K., Nodora, R. G., \& Ruppel, A. (2012). Assessment of factors influencing retention in the Philippine National Rural Physician Deployment Program. BMC Health Services Research, 12(1), 411. doi:10.1186/1472-6963-12-411

Lozada-Santone, P. C. (2001). Resiliency and the role of protective factors among Latino university students (Doctoral dissertation). Available from ProQuest Dissertations and Theses database.

Marasigan II, D. D., Dasas, D. K. A., Hernandez, F. G. R., Jayme, R. A., \& Alipio, M. M. Influence of Locus of Control and Motivation on Academic Success of First Year Radiologic Technology Students of a Higher Education Institution.

McIntyre, T. M., McIntyre, S. E., \& Francis, D. J. (2017). Educator Stress: An Occupational Health Perspective: Springer International Publishing.

McKay, M. (2009). Self-esteem: Easyread Edition: CREATESPACE PUB. 
Monroe, S. M., \& Kelley, J. M. (1997). Measurement of stress appraisal. Oxford University Press: New York.

Morcke, A. M., Dornan, T., \& Eika, B. (2013). Outcome (competency) based education: an exploration of its origins, theoretical basis, and empirical evidence. Advances in Health Sciences Education, 18(4), 851-863.

Mwavita, M., \& Thompson, D. (2006). Help-Seeking Behavior Among Freshmen Engineering Students: A Predictor of Calculus Performance. American Society for Engineering Education.

NEDA. (2017). Philippine Development Plan 2017-2022. 12 St. Josemaria Escriva Drive, Ortigas Center, Pasig City 1605 Philippines Retrieved from http://www.neda.gov.ph/.

Neuville, S., Frenay, M., \& Bourgeois, E. (2007). Task value, self-efficacy and goal orientations: impact on self-regulated learning, choice and performance among university students. Psychologica Belgica, 47.

Norman, P., \& Conner, M. (2017). Health Behavior. Reference Module in Neuroscience and Biobehavioral Psychology. doi:https://doi.org/10.1016/B978-0-12-809324-5.05143-9

Ogbeide, E., \& Ugwu, C. (2016). Relationship between social support and academic performance among undergraduate students of Madonna University, Nigeria. Global Journal of Applied, Management and Social Sciences (GOJAMSS), 13, 70-77.

Oreta, A., \& Roxas, C. (2012). Implementing an Outcomes-Based Education Framework in the Teaching of Engineering Mechanics (Statics)) International Conference on Civil Engineering Education, 1.

Payakachat, N., Gubbins, P. O., Ragland, D., Norman, S. E., Flowers, S. K., Stowe, C. D., . . . Hastings, J. K. (2013). Academic Help-Seeking Behavior Among Student Pharmacists. American Journal of Pharmaceutical Education, 77(1), 7. doi:10.5688/ajpe7717

Petersen, I.-h. (2006). Psychosocial factors and academic performance among first-year financial aid students: Testing adjustment as a mediator variable (Master of Social Science in Research Psychology ), University of Cape Town

Plante, I., O'Keefe, P., \& The'ore^t, P. (2012). The relation between achievement goal and expectancy-value theories in predicting achievement-related outcomes: A test of four theoretical conceptions. Springer Science+Business Media. doi:DOI 10.1007/s11031-012-9282-9

Republic Act 10533: Enhanced Basic Education Act of 2013. Philippines.

Rosenberg, M. (1965). Society and the adolescent self-image. Princeton, NJ: Princeton University Press.

Rosli, Y., Othman, H., Ishak, I., Lubis, S., Omar, B., \& Mohd Saat, N. (2011). Self-esteem and Academic Performance Relationship Amongst the Second Year Undergraduate Students of Universiti Kebangsaan Malaysia, Kuala Lumpur Campus (Vol. 60).

Rumberger, R., \& Ah Lim, S. (2008). Why Students Drop Out of School: A Review of 25 Years of Research.

Sæle, R. (2016). Academic performance and student dropout: Results from two studies in upper secondary and higher education in Northern Norway. (Doctor of Philosophy), UiT The Arctic 
University of Norway, Faculty of Health Sciences.

Sanchez, H., Outley, C., Gonzalez, J., \& Cascante, D. (2018). The Influence of Self-Efficacy Beliefs in the Academic Performance of Latina/o Students in the United States: A Systematic Literature Review. Hispanic Journal of Behavioral Sciences 4O(2), 176 - 209. doi:http://journals.sagepub.com/doi/10.1177/0739986318761323

Schunk, D., Pintrich, P., \& Meece, J. (2008). Motivation in Education: Theory, Research, and Applications: Pearson/Merrill Prentice Hall.

Sommer, M. (2013). Psychosocial Factors Predicting the Adjustment and Academic Performance of University Students. (Doctor of Philosophy), University of South Africa.

Suhaimi, F., \& Hussin, N. (2017). The Influence of Information Overload on Students' Academic Performance. International Journal of Academic Research in Business and Social Sciences, Human Resource Management Academic Research Society, International Journal of Academic Research in Business and Social Sciences, 7(8), 761-766.

Urdan, T., \& Pajares, F. (2006). Self-Efficacy Beliefs of Adolescents: Information Age Publishing, Incorporated.

Usher, E., \& Pajares, F. (2008). Sources of Self-Efficacy in School: Critical Review of the Literature and Future Directions. 78, 751-796. doi:10.3102/0034654308321456

Velez, E. (2014). America's College Drop-Out Epidemic: Understanding the College Drop-Out Population.

American Institutes for Research.

Verhoeven, P. (2010). Quality in statistics education: applying expectancy value models to predict student outcomes in statistics education. International Association of Statistical Education (IASE).

von Stumm, S., Hell, B., \& Premuzic, T. (2011). The Hungry Mind:Intellectual Curiosity Is the Third Pillar of Academic Performance. Perspectives on Psychological Science, 6(6), 574-588. doi:10.1177/1745691611421204

Wentzel, K., \& Miele, D. (2016). Handbook of Motivation at School: Taylor \& Francis.

Williams, D. (2010). Outcome expectancy and self-efficacy: theoretical implications of an unresolved contradiction. Pers. Soc. Psychol. doi:10.1177/1088868310368802

Xiang, P., McBride, R., \& Bruene, A. (2006). Fourth graders' motivational changes in an elementary physical

education running program. Research Quarterly for Exercise and Sport, 77, 195-207.

Zerna, E., Cruz, R., \& Nuqui, A. (2014). Factors Affecting Retention and Attrition Rates of La Consolacion University Philippines: Examining Students' Experiences. International Journal of Trends in Economics Management and Technolog, 3(2). 